\title{
Improvement of methods of evaluation of investment projects in the context of import substitution
}

\author{
M.S. Kuvshinov ${ }^{1, *}$, and N.S. Komarova ${ }^{1}$ \\ ${ }^{1}$ South Ural State University, Chelyabinsk, Russia
}

\begin{abstract}
Due to the imposition of sanctions, based more on geopolitical interests, there were additional essential restrictions on sources of external credits, use of import raw materials and technologies, possibilities of attraction to work of the qualified employees which do not have the Russian nationality, participation in the international technology and scientific projects. At similar restrictions of different resources investment decisions are made extremely carefully, and especially careful and reasonable efficiency evaluation of the investments is required. Traditionally used techniques of efficiency evaluation of investment projects not fully consider strategic interests of owners of industrial enterprises and investors. Decrease in risks requires higher quality of project evaluation. In this work the method of multi-level consistently complex integral assessment of investment projects on an indicator of the integral indicator of their efficiency implementing consecutive selection of investment projects from a portfolio on essential indicators of commercial effectiveness, efficiency of production business activities, a financial state and productivity of activity is provided. The developed method of a complex assessment of investment projects is implemented for practical application by the software product allowing to create on the basis of economic-mathematical modeling specific recommendations in economic practice of industrial enterprises during the developing and implementation of investment strategies. The conclusion that for the Russian economy in the conditions of import substitution accounting of all set of interests of investors and owners of the enterprises provides development and implementation of reasonable investment strategies is drawn.
\end{abstract}

\section{Introduction}

Paramount tasks of industrial enterprises always there is a development and modernization of production for ensuring competitiveness for the realization account of implementation and expansion of production volumes of new types of products $[1,2]$. In modern market conditions on search of sources of investment additional factors in the form of sanctions from one states are imposed on others. Such sanctions are based not only on economic interests, but essential weight is purchased also by geopolitical interests of participants of the market. As a result of it there are essential restrictions on sources of external credits, use of import raw materials and technologies, possibilities of attraction to work of the qualified employees which do not have the Russian nationality, participation in the international technology and scientific projects [3-8].

\section{Relevance of research}

Under similar conditions of restrictions of financial, material and human resources investment decisions are made extremely carefully, and especially careful and reasonable efficiency evaluation of the investments is required. Traditionally used techniques of efficiency evaluation of investment projects developed for a long time [9 - 11] not fully consider strategic interests of owners of industrial enterprises by opportunities of use of the available or again purchased resources for implementation of the planned investment projects during the periods after their end. To reduce risks, including unpredictable completions investment projects require high quality assessments of their effectiveness.

The operating techniques of an assessment of investment projects are based on procedure of discounting and calculation of mainly base indicators of productivity of investments (the net present profit (NPV), an internal return rate (IRR), an index of profitability (PI), a payback period (PP)). These techniques [11] not always allow to make a reasonable choice for the most effective project. In the projects having high rates of productivity of investments, the investor can be not satisfied since he can be interested not only in profitability and an investment payback, but also other indicators such as reflecting strategic objectives of development of the enterprise regarding efficiency of production business activities, a financial state, social development, etc. which for each enterprise and the investment project can have the structure and the acceptable values.

\footnotetext{
Corresponding author: msk1954@mail.ru
} 


\section{Problem statement}

At accomplishment of a choice of one investment project from a portfolio of projects in the conditions of sanctions restrictions there are questions of the approved application of the main indicators of productivity of project data (NPV, IRR, PI, PP): in projects with the different volume of investment, identical NPV values can be received; occurs in the projects having high NPV value situations when IRR value is much lower, than in projects with lower NPV value; in projects with the different volume of investment and NPV, almost identical PI values can be received; the payback period does not estimate cash flows outside a point of an investment payback and is used only in addition to other criteria of efficiency.

In such situation there is a problem of improvement of quality of examination of efficiency of investment projects on the basis of the complex assessment reflecting, both interests of investors, and interests of the enterprises implementing project portfolios, and based not only on comparison of traditional indicators (NPV, IRR, PI, PP), but also considering all set of the criteria interesting the investors united in a uniform integral indicator of efficiency evaluation of the considered projects. Expansion of completeness of examination increases definiteness of a choice and reduces risks of justification of a choice.

Improvement of techniques of an assessment in this sphere allows to avoid more than probable essential economic losses during the developing and implementation of investment projects and defines relevance of work.

Works of many foreign [2, 12] and Russian authors [13 - 16], including works of a historical retrospective are devoted to problems of efficiency evaluation of the investment projects aimed at the production development [9].

The purpose of work is improvement of methodical tools of a complex assessment of investment projects on the industrial enterprises working in the conditions of sanctions restriction of resources.

\section{Development of evaluation methods}

Flexible and effective management of investments taking into account action of sanctions factors requires an assessment of their efficiency, as for all term of implementation of the investment project, and on each specific current step during all stages of project lifecycle, including an end stage.

The variety of options and the parties of implementation of investment projects, and their results, creates variety of options of an assessment of their efficiency.

Performance indicators of projects are calculated on the basis of forecast cash flows and depend on regulation of the income which, is defined subjectively and influences their size. Each of the indicators has its own purpose and reflects its incorporation of side, but they have a different dimension and do not always have a direct interdependence of the patterns. Therefore each separate indicator cannot be used as the only criterion of efficiency.

Flexible and effective management of investment processes taking into account changes of the external and internal environment is reached by improvement of quality of efficiency evaluation at the expense of the approved choice of the measure values satisfying sets of requirements of investors and used in efficiency evaluation of projects, definiteness and a correctness of use of the main criteria of efficiency, accounting of specific features of activity of industrial enterprises when carrying out efficiency evaluation of projects from a portfolio and practical recommendations for a choice of the best of alternative options.

More complete examination of investment projects has to be provided due to use of the integral estimates considering both traditional, and other indicators representing essential interest for the investor during all stages of lifecycle including project completion.

Necessary completeness of examination is provided on the basis of an integral quantitative assessment which forms when using of the developed method of multilevel complex sequential estimation of efficiency of investment projects. The structure, stages and functions of such method are defined proceeding from accounting of modern specific features of implementation of investment projects in the conditions of action of the sanctions connected with modernization and technology updating of production, performance improvement of work and quality of products, implementation of innovations, decrease in labor input and costs [17].

A key element of its evaluation of the effectiveness of the investment project is risk monitoring their unpredictable conclusion at all stages of implementation. Incorrectly certain project scope, limitation of determination and risk management, an incorrectness of determination of main assumptions, a formalism or insufficient competence of procedure of carrying out efficiency evaluation of projects are basic reasons of risks of unsatisfactory end. Thus the factors influencing on not predicted project completion, influence the size of cash flows on them on which, in turn, performance indicators directly depend [18].

The variety, heterogeneity and divergence of influence of the initial indicators creating efficiency of investment projects, taking into account risks of the estimates using traditional performance indicators, and unanticipated risks completions when you post all the essential interests of an investor determine the tools implement multilevel method integrated coherent assessment. As such tools acceptability indicators for investors of the used initial indicators, efficiency indicators in the directions of an assessment and the integral indicator of efficiency of the investment project in general act. Thus unacceptability of the current results of an assessment at any stage of work of the used method has to have impact on the level of requirements of the investor to the considered indicators. In connection therewith are defined structure of stages of complex efficiency evaluation of investment projects where consistently from a portfolio constantly 
decreasing sets of the most acceptable projects are selected.

At the first stage efficiency evaluation of projects in general on traditional indicators of productivity of investments (NPV $>0$, IRR $>\mathrm{E}, \mathrm{PI}>1, \mathrm{PP}<\mathrm{T}$, where $\mathrm{E}-$ a discount rate, $\mathrm{T}$ - project term is carried out). Accomplishment of these conditions in different degree for several projects from a portfolio creates a problem of a choice of a set of the NPV, IRR, PI and PP values satisfying all set of essential requirements of investors.

To ensure that the integrated impact of investment performance indicators (NPV, IRR, PI, PP) on the effectiveness of the project on their basis is determined by a quantitative indicator of commercial efficiency $\left(E I_{c e}\right)$.All calculations were carried out based on two real industrial enterprises when using the group of experts from the interested specialists. Using a method of analysis of hierarchies defined the composition of the most relevant indicators, coefficients of the weight and importance of each indicator used in the formation of $\mathrm{EI}_{\mathrm{ce}}$, for the analyzed enterprises. Were their part: the net present profit, an internal return rate, an index of profitability and a payback period with weight coefficients respectively 0,$338 ; 0,406 ; 0,160$ and 0,096 . Comparability of indicators is reached by reduction of indicators to uniform basis [19]. As a result, expression of the indicator of the generalized commercial effectiveness of $E I_{c e}$ has an appearance:

$$
E I_{c e}=U_{i=1}^{n} I A_{i} / \sqrt{\sum_{i=1}^{k} v_{i}\left(1-I_{i}\right)^{2}+\sum_{i=k+1}^{n} v_{i} I_{i}^{2}},
$$

where $I A_{i}$ - indicators of the acceptability of the considered indicators; $I_{i}$ - the given values of the considered indicators on the current step of calculation; $v_{i}$ - weight coefficients; $n$ - total quantity of the considered indicators; $\mathrm{k}$ - the quantity of the considered indicators which increase leads to increase in $E I_{c e}$, and leads increase in the others to reduction of $E I_{c e}$.

In turn, the given indicators are defined with production scale as:

$$
I_{i j}=p_{i j} / \max \left(p_{i j}\right)
$$

where $p_{i j}-i$ values of an indicator for $j$ of the project or option of its implementation; $\max \left(p_{i j}\right)-$ the maximum $i$ value of an indicator from all number of the compared projects or options of their implementation.

The structure of the considered indicators is open system, considers essential interests of specific owners and investors of the specific enterprises and can be changed in any party. As a part of the increasing indicators for the considered enterprises the net present profit, an internal return rate and an index of profitability, and as a part of the reducing indicators - a payback period.

Indicators of the acceptability of indicators of $I A_{i}$ accept "acceptable" (1) or "unacceptable" (0) values according to the acceptability for the investor. If, at least we do not accept one indicator of the acceptability, $E I_{c e}$ $=0$ and it is necessary to refuse implementation of the investment project at this level of requirements of the investor, or to approve with it the level of requirements. If, all indicators of the acceptability conforms to requirements, the stage is necessary complete.

The generalized indicator of commercial effectiveness of $E I_{c e}$ allows to resolve issues of approval of a choice of the measure values used in efficiency evaluation of investment projects with set of interests of investors, and also a choice of the main indicator on which it is necessary to draw a conclusion on efficiency of the project as at its determination all standard indicators of commercial effectiveness in total, taking into account their weight importance and an orientation of influence were considered.

In the conditions of action of sanctions modernization and technology updating of production, performance improvement of work and quality of products, implementation of innovations, decrease in labor input and costs are a necessary condition of effective functioning of industrial enterprises on achievement of cumulative strategic objectives of development, including the post-project periods. Therefore even in the projects having high rates of commercial effectiveness of investments for increase of completeness of examination and decrease in risks it is necessary to consider the indicators reflecting efficiency of the production business activities $(P B A)$, financial state, etc. which for each enterprise and each investment project can have the structure and the acceptable values.

Indicators of commercial effectiveness have no direct interdependence with $P B A$ indicators. In connection therewith, the second obligatory stage of examination of investment projects is impact assessment of its implementation on production business activities of the enterprise on the basis of calculation of the quantitative indicator of the generalized efficiency of production business activities of $E I_{p b a}$.

The generalized indicator of efficiency of influence of $E I_{p b a}$ allows to judge influence of implementation of investment process on market provision of the enterprise, efficiency of use of fixed assets, resources and, at the expense of it, on a profit gain. The $E I_{p b a}$ indicator is based on components of indicators, taking into account their relevance coefficients $v_{i}$.

The significance of the values of the coefficients in the Group of indicators on the impact of the investment process in the enterprise economical activity are defined similarly to the previous case. For the analyzed enterprises coefficients of updating of fixed assets, capital productivity, the impact of the salary, profitability of sales, a market share, scope change of sales, profitability of products, investment profitability, a return materials and power return with weight coefficients respectively were their part: 0,$16 ; 0,204$; 0,$120 ; 0,164 ; 0,098 ; 0,055 ; 0,071 ; 0,057 ; 0,041$ and 0,028 .

The indicator of efficiency of influence of implementation of investment process on production business activities of the $E I_{p b a}$ enterprise is defined with weight coefficients, an orientation of influence and heterogeneity of the indicators taken into account on expression: 


$$
E I_{p b a}=U_{i=1}^{m} I A_{i} / \sqrt{\sum_{i=1}^{m} v_{i}\left(1-I_{i}\right)^{2}}
$$

where $m$ - quantity of the considered indicators which increase leads to increase in $E I_{p b a}$. Other designations correspond to a formula (1) for coefficients of updating of fixed assets, capital productivity, a impact of salary, profitability of sales, a market share, scope change of sales, profitability of products, investment profitability, a impact of materials and power return

The assessment of financial productivity on the basis of calculation of the generalized indicator of financial productivity of $E I_{f p}$ allows to consider financial return on the invested capital, cash flows, a property gain as a result of implementation of the investment project, change of liquidity and financial stability of the enterprise, and is the third obligatory stage of examination of projects.

Weight coefficients for the considered indicators creating $E I_{f p}$ are calculated by method of the analysis of hierarchies to similarly previous cases. Coefficients of a gain of revenue, gain of profit, a gain of property, overall liquidity and financial stability with weight coefficients respectively were their part for the analyzed enterprises: 0,$105 ; 0,427 ; 0,099 ; 0,184$ and 0,184 . Comparability of indicators is reached by reduction of indicators to uniform basis to similarly previous stages.

The generalized indicator of influence of implementation of investment process on a financial state and productivity of activity of the $\mathrm{EI}_{\mathrm{fp}}$ enterprise is determined by expression:

$$
E I_{f p}=U_{i=1}^{l} I A_{i} / \sqrt{\sum_{i=1}^{l} v_{i}\left(1-I_{i}\right)^{2}},
$$

where $l$ - quantity of the considered indicators which increase leads to increase in $E I_{f p}$. Other designations correspond to a formula (1) for coefficients, a gain of revenue, a gain of profit, a gain of property, overall liquidity and financial stability.

Improvement of quality of an assessment of investment projects at the expense of the most complete examination of their efficiency on the basis of use of the integral estimates considering indicators of productivity of investments (NPV, IRR, PI, PP), and also other performance indicators of production business activities, a financial state and productivity of the enterprise which are of interest to the investor allows to reduce risks of efficiency evaluation of projects, including risks of their unpredictable completions. Determination of the integral indicator of efficiency of the investment projects IEI is the fourth obligatory stage of examination.

Examination is carried out in the comparative analysis of several investment projects from a portfolio on a rating of integral indicators of efficiency. In case of an assessment of one investment project the comparative analysis is made with the virtual project analog to which on expert evaluation the project analog with the average market indicators accepted in the current sales terms is accepted. In the presence of several options of implementation of one investment project they are accepted to a portfolio. Thus in all options of calculations at each intermediate settlement stage monitoring of probability of not predicted end is carried out. For the chosen investment project, in the presence of opportunity, adjustment of sizes of the most significant parameters influencing increase in an assessment of the integral indicator of efficiency can be carried out.

The selected investment project which most meets expectations of investors on all set of the accepted performance indicators is result of work of the developed method of a complex assessment.

Actually integral efficiency evaluation of projects forms on the basis of the private generalized indicators: indicator of commercial effectiveness of $E I_{c e}$, indicator of efficiency of influence of implementation of the investment project on production business activities of the $E I_{p b a}$ enterprise and indicator of influence of implementation of the investment project on a financial state and productivity of activity of the $E I_{f p}$ enterprise.

The integral indicator of efficiency of the investment project implements the second level of a method, is a complex assessment, is defined according to expression:

$$
I E I=1 / \sqrt{\left(1-E I_{c e}\right)^{2}+\left(1-E I_{p b a}\right)^{2}+\left(1-E I_{c e}\right)^{2}},
$$

In case of comparison of the estimated project with the project analog and strategic expediency of its implementation the scale of levels of the acceptability for the integral $I F_{I E I}$ indicator is recommended: $0 \ldots 0,66-$ risky; $0,67 \ldots 0,75$ - satisfactory; $0,76 \ldots 0,9$ - acceptable; $0,91 \ldots 1,0$ - high where $I F_{I E I}^{\max }=1$ corresponds to a maximum level of $I F_{I E I}$ of ap of the project analog.

Action of the offered method is implemented by consecutive use of settlement stages when monitoring the acceptability of values of the used parameters according to requirements of interests of investors.

Project evaluation from a portfolio in general on the commonly accepted indicators of productivity of investments carries out allocation of the projects necessary for the enterprise for business development in the conditions of action of sanctions with use of instruments of strategic management. After making decision on compliance of the investment project to strategic objectives of the enterprise transition to project evaluation in general on the commonly accepted indicators of productivity of investments (NPV, IRR, PI, PP) is carried out.

The project scope is defined proceeding from the level of profitability, capacity and tendencies of the market, and also with the analysis of activity of main competitors.

At a choice of main assumptions (according to the decision of developers): in long-term projects the annual rate of discounting should be calculated according to a forecast rate of inflation of every year; the discount rate for the different markets needs to be calculated according to different risk level for the different markets; in real economy as the minimum regulation of the income it is necessary to accept industry profitability of the capital; when using loan financing of projects as the minimum regulation of the income it is necessary to use the size of an annual interest rate on the credit; when using of the mixed financing of projects it is necessary to apply a method of the weighted average capital cost (WACC) to determination of a discount rate; when carrying out sensitivity analysis of the 
project it is necessary to define sensitivity of the project to different discount rates for identification of limits of stability of the project and acceptable regulation of the income of the project. It is necessary to consider transition of Central Bank of the Russian Federation to a key rate.

For duration of a settlement period the term of return of investments, or the period during which the investment project will make required profit is assumed as a basis. However, thus the increase in lifecycle or term of implementation of such project reduces reliability of calculation and an assessment of performance indicators. It is necessary to consider possibility of flexible decrease (increase) of the production volume and implementation according to demand in subsequent periods reflecting dynamics of probable emergence and removal of sanctions.

In the course of an assessment of long-term projects, owing to irregularity and non-equivalence in time of cash flows, for increase of reliability of efficiency evaluation it is necessary to use more rhythmic step of calculation equal to half-year, quarter or month.

In the presence of a positive integral assessment the decision on expediency of project implementation or on a choice of one of the compared versions of projects of an assessment by criterion of $\max \left\{I E I_{i}\right\}$ is made. In the presence of possibility of adjustment of the most significant parameters influencing increase in IEI taking into account interests of investors their adjustment at the sixth stage with the subsequent transition to implementation of the selected investment project is carried out.

The project chosen on the basis of the offered method to implementation most fully considers all set of interests of investors.

For correction of the most significant the indicators having the greatest weight as a part of the generalized indicators of efficiency and $I E I$ which are most influencing the integral indicator of efficiency are selected. Such approach allows to develop actions for management of the factors influencing efficiency of the investment project according to the forecast of change of its integral indicator of efficiency and to create practical recommendations about achievement of target values according to interests of investors.

For determination or approach to target values of private indicators at performance management of projects the method of interval estimates is used. The private indicator of $p_{i j}$ has to is in "a trust interval" which is the solution of an inequality:

$$
\overline{p_{i j}}-t \sigma / \sqrt{n}<p_{i j}^{a}<\overline{p_{i j}}+t \sigma / \sqrt{n},
$$

where $p_{i j}^{a}$ - acceptable $i$ value of an indicator for $j$ of the project or option of its implementation; $\overline{p_{i j}}-$ mean value of $i$ an indicator for $j$ of the project or option of its implementation; $\sigma-$ an average quadratic deviation of $i$ an indicator for $j$ of the project or option of its implementation from mean value of $i$ an indicator for $j$ of the project or option of its implementation; $t$ - value of argument of function of Laplace; $n$ - amount of forecast $i$ values of an indicator for $j$ of the project or option of its implementation (selection volume).

\section{The practical significance and results of testing}

The received results of calculations of confidential intervals allow to reveal admissible fluctuations of private indicators of efficiency and to make the decision on implementation of investment projects. When you run a select one project from a portfolio of preferred options that match $\max \left\{I E I_{i}\right\}$. interval estimation and allows you to set the boundaries of the ranges of allowable fluctuations of the best composed performance indicators. The calculations which are carried out as a result of economic-mathematical modeling on materials of experimental approbation of the developed technique will be approved with the commonly accepted provisions and confirm them taking into account use of set of the indicators essential to investors in a complex.

Developed by authors a method of a multi-level sequential integral estimation of investment projects it is used when developing the software product based on the tabular MS Excel [20] processor by means of which the assessment of investment projects of industrial enterprise LTD "Uralspetstrans" was carried out (Miass) where experimental approbation of the developed method was carried out. The complex evaluation method allowed to make a reasonable choice for benefit of the most effective project (table I).

It is established that using the commonly accepted evaluation methods of efficiency of projects on a set of ratios of $\mathrm{NPV}>0, \mathrm{IRR}>\mathrm{E}, \mathrm{PI}>1, \mathrm{PP}<\mathrm{T}$ without integral approach can be made the wrong decision on a choice of one project from a portfolio. Multi-level complex an evaluation method is more exact and allows to make a reasonable choice for benefit of the effective project.

Table 1. Approbation of results of research.

\begin{tabular}{|c|c|c|c|c|c|c|c|}
\hline Indicator & 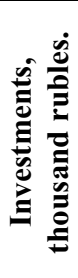 & 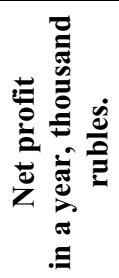 & 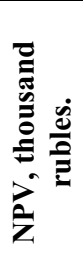 & $\frac{\partial^{\circ}}{\underline{\alpha}}$ & ? & 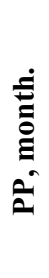 & 돌 \\
\hline $\begin{array}{l}\text { Production } \\
\text { of } \\
\text { automobile } \\
\text { tanks }\end{array}$ & 2140 & 721 & 1602 & 61 & 1.7 & 21 & 2.1 \\
\hline $\begin{array}{l}\text { Production } \\
\text { of hoses of } \\
\text { automobile } \\
\text { cooling } \\
\text { systems }\end{array}$ & 1558 & 901 & 895 & 51 & 1.6 & 18 & 2.4 \\
\hline
\end{tabular}

\section{Conclusion}

Thus, to reduce risks, including unpredictable completions investment projects you want to improve the quality of assessments of their effectiveness on the basis of their expertise more fully through the use of integrated assessments that take into account both traditional and other indicators that represent a 
significant concern for investors. The offered multi-level method of a complex assessment of investment projects of industrial enterprises allows to estimate efficiency more fully by means of the uniform integral indicator considering set of interests of investors, providing thereby development and implementation of reasonable investment strategies.

The work was supported by Act 211 Government of the Russian Federation, contract № 02.A03.21.0011.

\section{References}

1. Yu.V. Babanova, V.V. Tomasheva, Finance and credit, 46, 27-32 (2012)

2. Yu. Brigkhem, M. Erkhardt, Financial management (Transfer with English SPb, St. Petersburg, 2007)

3. R. Asankin, Europe and Turkey will close the markets for the Russian metallurgists. http://www.rbc.ru/business/28/01/2016/56aa053f9a7 947cee59701a6.

4. M.S. Ivanova, World of Science Internet magazine, 1 (2015). http://mir-nauki .com/PDF/26EMN115.pdf.

5. V.S. Luganov, Economic effects for Russia from economic sanctions. http://itar-tass .com/opinions/1597242.

6. V. Tkachyov, Investments in the conditions of sanctions. http://www.tn.ru/about/press/news/ investicii v uslovijah sankcij.

7. N.V. Klimova, S.Yu. Murashkina, Influence of sanctions on the investment climate and industrial policy of Russia. http://cyberleninka.ru/article/n/vliyanie-sanktsiy-nainvestitsionnyy-klimat-i-promyshlennuyu-politikurossii.

8. The federal law of May 19, 2010 No. 86-FZ "About modification of the Federal law of July 25, 2002 No. 115-FZ. http://pravo.gov.ru/ proxy/ips/?docbody=\&nd=102138471.
9. A technique of determination of cost efficiency of implementation of new equipment, mechanization and automation of production processes in the industry.http://www.libussr.ru/doc_ussr/usr_5750.ht $\mathrm{m}$.

10. The federal law of February 25, 1999 No. 39-FZ. http://pravo.gov.ru/proxy/ips/?docbody $=\& n d=10205$ 8332.

11. Methodical recommendations about efficiency evaluation of investment projects no. VK-477 of 1999.http://www.consultant.ru/document/cons_doc_ LAW_28224.

12. 15 Causes of Project Failure by M. Symonds. http://www.projectsmart.co.uk/pdf/15-causes-ofproject-failure.pdf.

13. A.Yu. Ruban, Forming of the controling mechanism investment projects (Ufa, 2010)

14. Electronic consulting. Factor analysis. http://www.distcons.ru/modules/DuPont/section2.html.

15. S.L. Glekov, The mechanism of adoption of investment decisions taking into account alternative" efficiency - reliability (Moscow, 2011)

16. M.G. Litke, Economic evaluation and management of the innovation projects of small and medium business at the mesolevel (Chelyabinsk, 2012)

17. N.V. Matveev, Methods of a complex assessment of investment projects (St. Petersburg, 2007)

18. M.I. Rimer, Economic evaluation of investments: The textbook for higher education institutions (Peter, St. Petersburg, 2014)

19. M.S. Kuvshinov, Economic analysis: theory and practice, 7, 30-38 (2014)

20. M.S. Kuvshinov, N.S. Komarova, Calculation of cost efficiency of investment projects of industrial enterprises: program (RU state registration program, 50201450091) 